\title{
Role of vesicular monoamine transporter type 2 in rodent insulin secretion and glucose metabolism revealed by its specific antagonist tetrabenazine
}

\author{
Anthony Raffo ${ }^{1}$, Kolbe Hancock ${ }^{2}$, Teresa Polito ${ }^{1}$, Yuli Xie ${ }^{1}$, Gordon Andan ${ }^{3}$, Piotr Witkowski, ${ }^{3,4}$ \\ Mark Hardy ${ }^{3}$, Pasquale Barba ${ }^{5}$, Caterina Ferrara ${ }^{5}$, Antonella Maffei ${ }^{1,5}$, Matthew Freeby ${ }^{1}$, Robin Goland ${ }^{6}$, \\ Rudolph L Leibel ${ }^{\mathbf{6}}$, Ian R Sweet ${ }^{7}$ and Paul E Harris ${ }^{\mathbf{1}}$ \\ ${ }^{1}$ Department of Medicine, BB 20-06, Columbia University Medical Center, 650 West 168th Street, New York, New York 10032, USA \\ ${ }^{2}$ Barnard College, Columbia University, New York, New York 10027, USA \\ ${ }^{3}$ Department of Surgery of Columbia University Medical Center, New York, New York 10032, USA \\ ${ }^{4}$ Department of Surgery, Medical University of Gdansk, Gdansk 80-952, Poland \\ ${ }^{5}$ Institute of Genetics and Biophysics 'Adriano Buzzati-Traverso', CNR, Naples 80131, Italy \\ ${ }^{6}$ Naomi Berrie Diabetes Center, Columbia University Medical Center, New York, New York 10032, USA \\ ${ }^{7}$ Department of Medicine, University of Washington, Seattle, Washington 98195, USA \\ (Correspondence should be addressed to P E Harris; Email: peh1@columbia.edu)
}

\begin{abstract}
Despite different embryological origins, islet $\beta$-cells and neurons share the expression of many genes and display multiple functional similarities. One shared gene product, vesicular monoamine transporter type 2 (VMAT2, also known as SLC18A2), is highly expressed in human $\beta$-cells relative to other cells in the endocrine and exocrine pancreas. Recent reports suggest that the monoamine dopamine is an important paracrine and/or autocrine regulator of insulin release by $\beta$-cells. Given the important role of VMAT2 in the economy of monoamines such as dopamine, we investigated the possible role of VMAT2 in insulin secretion and glucose metabolism. Using a VMAT2-specific antagonist, tetrabenazine (TBZ), we studied glucose homeostasis, insulin secretion both in vivo and ex vivo in cultures of purified rodent islets. During
\end{abstract}

intraperitoneal glucose tolerance tests, control rats showed increased serum insulin concentrations and smaller glucose excursions relative to controls after a single intravenous dose of TBZ. One hour following TBZ administration we observed a significant depletion of total pancreas dopamine. Correspondingly, exogenous L-3,4-dihydroxyphenylalanine reversed the effects of TBZ on glucose clearance in vivo. In in vitro studies of rat islets, a significantly enhanced glucose-dependent insulin secretion was observed in the presence of dihydrotetrabenazine, the active metabolite of TBZ. Together, these data suggest that VMAT2 regulates in vivo glucose homeostasis and insulin production, most likely via its role in vesicular transport and storage of monoamines in $\beta$-cells.

Journal of Endocrinology (2008) 198, 41-49

\section{Introduction}

D-Glucose, with the synergistic effects of certain amino acids, is the major physiological stimulus for insulin secretion (reviewed in Henquin (2000)). The net insulin production and glucose homeostasis, however, are regulated by a number of other molecules, including several classical neurotransmitters (Brunicardi et al. 1995, Ahren 2000) that act directly on $\beta$-cells, and indirectly through other target tissues such as liver and skeletal muscle. Many of these molecules function as amplifying agents that have little or no effect by themselves, but enhance the signals generated by the $\beta$-cell glucose sensing apparatus (Henquin 2000). For example, during the cephalic phase of insulin release, acetylcholine (ACh) is released via islet parasympathetic innervation. $\beta$-Cells express the M3 muscarinic receptor (Duttaroy et al. 2004) and respond to exogenous ACh with increased inositol phosphate production, which in turn facilitates the $\mathrm{Na}+$ ion exit and calcium ion entry. This results in an augmented insulin vesicle exocytosis (Barker et al. 2002). The amino acid glutamate, the major excitatory neurotransmitter in the central nervous system, is present in both $\alpha$ - and $\beta$-cells of the endocrine pancreas. Glutamate is stored in glucagon-containing granules (Hayashi et al. 2003), and is proposed to enhance insulin secretion when it is released into the vicinity of islet cells (Storto et al. 2006). The presence of metabotropic glutamate receptors on $\alpha$ - and $\beta$-cells themselves suggests the presence of both autocrine and paracrine circuits within islet tissue involved in the regulation of insulin secretion (Brice et al. 2002). 
Other neurotransmitters, such as the monoamines, epinephrine, and norepinephine, acting both systemically and via nerve terminals in the vicinity of islets, may act to suppress the glucose-stimulated insulin secretion by direct interaction with adrenoreceptors expressed (mainly the $\alpha 2$ receptor) on pancreatic $\beta$-cells (El-Mansoury \& Morgan 1998, Ahren 2000). $\beta$-Cells of the endocrine pancreas also express dopamine receptors (D2) and respond to exogenous dopamine with inhibited glucose-stimulated insulin secretion (Ahren \& Lundquist 1985, Niswender et al. 2005, Rubi et al. 2005, Shankar et al. 2006). Purified islet tissue is a source of monoamines, and has been shown to contain 5-hydroxytryptamine, epinephrine, norepinephrine, and dopamine (Cegrell 1968, Ekholm et al. 1971, Wilson et al. 1974, Hansen \& Hedeskov 1977, Lundquist et al. 1989, Niswender et al. 2005).

$\beta$-Cells also have the biosynthetic apparatus to create, dispose of, and store specific neurotransmitters. For example, tyrosine hydroxylase, the enzyme responsible for catalyzing the conversion of L-tyrosine to L-3,4-dihydroxyphenylalanine (L-DOPA), a precursor of dopamine, L-DOPA decarboxylase, responsible for converting L-DOPA to dopamine (Rubi et al. 2005) and dopamine beta hydroxylase, the enzyme that catalyzes the conversion of dopamine to norepinephrine, are present in the islet tissue (Iturriza \& Thibault 1993, Borelli et al. 2003). Thus, L-DOPA is rapidly converted in the islet $\beta$-cells to dopamine (Ahren et al. 1981, Borelli et al. 1997). Monoamine oxidase (MAO) is a catabolic enzyme responsible for the oxidative deamination of monoamines, such as dopamine and catecholamines, and maintains the cellular homeostasis of monoamines. The possible role of MAO in islet function has been studied (Adeghate \& Donath 1991) and MAO has been detected in both $\alpha$ - and $\beta$-cells of pancreatic islet cells, including $\beta$-cells (Feldman \& Chapman 1975a,b). Interestingly, some MAO inhibitors have been shown to antagonize glucose-induced insulin secretion (Aleyassine \& Gardiner 1975). The secretory granules of pancreatic $\beta$-cells store substantial amounts of calcium, dopamine, and serotonin (Ahren \& Lundquist 1985).

In the central nervous system, the storage of monoamine neurotransmitters in secretory organelles is mediated by a vesicular amine transporter. These molecules are expressed as integral membrane proteins of the lipid bilayer of secretory vesicles in neuronal and endocrine cells. An electrochemical gradient provides energy for the vesicular packaging of monoamines, such as dopamine, for later discharge into the synaptic space (reviewed by (Eiden et al. 2004). Both immunohistochemistry and gene expression studies show that islet tissue and the $\beta$-cells of the endocrine pancreas selectively express only one member of the family of vesicular amine transporters, vesicular monoamine transporter type 2 (VMAT2; Anlauf et al. 2003).

Recent studies have shown the feasibility of noninvasive measurements of the amount of VMAT2 in the pancreas as a useful biomarker of $\beta$-cell mass both in humans ( $\mathrm{R}$ Goland personal communication) and in rodents (Souza et al. 2006) using $\left[{ }^{11} \mathrm{C}\right]$ dihydrotetrabenazine (DTBZ) and positron emission tomography, but the possible functional role of VMAT2, as expressed in islet tissue and $\beta$-cells, in glucose metabolism has not yet been explored.

As indicated, endogenously synthesized and/or stored monoamine neurotransmitters appear to participate in the paracrine regulation of insulin secretion and entrainment of the activity of various cells within islets (Borelli \& Gagliardino 2001). Given the important role of vesicular amine transporters in the storage and distribution of monoamine neurotransmitters, we explored the possible role of VMAT2 in glucosestimulated insulin secretion using the VMAT2-specific antagonist, tetrabenazine (TBZ; Scherman et al. 1983). TBZ acts as a reversible inhibitor of monoamine uptake into granular vesicles of presynaptic neurons (Pettibone et al. 1984) through its ability to bind to VMAT2 (Scherman 1986) thereby facilitating monoamine degradation by MAO. Monoamine neurotransmitters that are depleted via VMAT2 inhibition by TBZ include serotonin, dopamine, and norepinephine. The administration of TBZ to rats (plasma elimination $t_{1 / 2}=2 \mathrm{~h}$ ) reduces dopamine levels by $40 \%$, serotonin by $44 \%$, and norepinephrine by $41 \%$ in the brain (Lane et al. 1976). Although there are other vesicular amine transporters (e.g. VMAT1), TBZ is highly specific for VMAT2, binds to the transporter with a $K_{\mathrm{d}}$ in the nanomolar range, and displays a more than 10000 -fold reduced affinity towards VMAT1 (Erickson et al. 1996, Varoqui \& Erickson 1997). Given the known effects of monoamine neurotransmitters on insulin secretion, the expression of VMAT2 by $\beta$-cells and the antagonist action of TBZ on monoamine transport, we elected to study glucose metabolism and insulin secretion in vivo and in vitro following the treatment with TBZ.

\section{Materials and Methods}

\section{Drugs and reagents}

L-Epinephrine bitartrate, D-glucose, L-DOPA, and sodium citrate were obtained from Sigma Chemicals. All cell culture media and supplements were obtained from Invitrogen. Tissue culture plates were obtained from Falconware (Becton-Dickinson, Inc., Oxnard, CA, USA). TBZ and DTBZ were obtained from the National Institute of Mental Health's Chemical Synthesis and Drug Supply Program or Tocris Bioscience (Ellisville, MO, USA). All other chemicals were of the highest commercial quality available.

\section{Experimental animals}

All animal studies were reviewed and approved by the Institutional Animal Care and Use Committee at Columbia University's College of Physicians and Surgeons. All experiments were performed in accordance with the 'Principles of laboratory animal care' (NIH publication no. 85-23, revised 1985). Normal male Lewis rats were obtained 
from Taconic (Taconic, Inc., Germantown, NY, USA) and were housed under conditions of controlled humidity $(55 \pm$ $5 \%$ ), temperature $\left(23 \pm 1^{\circ} \mathrm{C}\right)$, and lighting (lights on: 0600$1800 \mathrm{~h}$ ) with access to standard laboratory Purina rat chow and water ad libitum. The rats were handled daily to minimize nonspecific stress for more than 7 days before the experiments began. In most experiments it was necessary to measure blood glucose (BG) in fasting animals. For these groups, food was removed at the beginning of the light cycle, $6 \mathrm{~h}$ before glucose levels were tested. Fasting rats for more than $8 \mathrm{~h}$ resulted in higher experimental variability. Sixty minutes prior to i.p. glucose tolerance testing (IPGTT), anesthesia of male Lewis rats was induced with isoflurane (3-4\% in oxygen) and maintained with $1-2 \%$ isoflurane in oxygen. The anesthetized rats were administered TBZ at the indicated dose by i.v. injection at the penile vein. TBZ or L-DOPA was dissolved in neat sterile DMSO and diluted (always more than tenfold) in sterile saline. The control rats received injections of the vehicle alone (10\% DMSO in saline). The animals were fully recovered for at least $30 \mathrm{~min}$ before receiving IPGTT. In specified experiments, L-DOPA was injected intraperitoncously at the specified dose at the initiation of IPGTT. An abnormal glucose tolerance was induced by a single i.p. injection of streptozotocin (STZ; Sigma-Aldrich) $(50 \mathrm{mg} / \mathrm{kg})$ to animals that had been fasted $4 \mathrm{~h}$ to enhance the efficacy of STZ. The STZ solution was prepared fresh by dissolving it in $0 \cdot 1 \mathrm{M}$ citrate buffer $(\mathrm{pH} 5 \cdot 5)$ and terminally sterile-filtered. Control Lewis age- and weight-matched rats received a $0.5 \mathrm{ml} / \mathrm{kg}$ citrate vehicle alone via i.p. injection. The diabetic phenotype induced by STZ was allowed to develop for 1 week before confirmation by glucose tolerance testing. The animals were considered to have a stable diabetic phenotype after three consecutive measurements of BG with a value of $>300 \mathrm{mg} / \mathrm{dl}$. Those animals failing this criterion were not used and killed.

\section{BG, insulin, glucagon, and i.p. glucose tolerance test measurements}

Blood samples were collected between 1200 and $1400 \mathrm{~h}$ from a superficial blood vessel in the tails of the rats following $6 \mathrm{~h}$ fasting. The fasting BG levels of the rats were measured using an Accu-Check BG monitoring system (Roche Diagnostics). IPGTT were performed in $6 \mathrm{~h}$ fasting un-anesthetized animals as described previously (Weksler-Zangen et al. 2001). Briefly, after baseline BG measurements, the animals received an i.p. injection of $2 \mathrm{~g}$ glucose $/ \mathrm{kg}$ body weight. To minimize stress during the procedure, the rats were handled by the same operator during acclimatization and later during weighing and IPGTT. Blood samples (50 or $150 \mu \mathrm{l}$ ) were collected at baseline and then again at 15 30, 60, 90, and $120 \mathrm{~min}$ following i.p. glucose. BG concentrations were measured immediately on these samples and the remainder processed. Plasma was immediately separated by centrifugation at $3000 \mathrm{~g}$ for $15 \mathrm{~min}$ and then stored at $-80{ }^{\circ} \mathrm{C}$ until analysis. Insulin and glucagon concentration measurements in rat plasma were performed by ELISA as per the manufacturer's instructions using kits from Linco Research, Inc. (St Charles, MI, USA) and Alpco Diagnostics (Salem, NH, USA) respectively. To validate the test, saline injections were performed using the same method. During this experiment, glucose concentration did not differ from baseline at each time point (data not shown). The area under the curve for insulin, glucagon and IPGTT glucose concentration $\times$ time curve (AUC IPGTT) was calculated using the trapezoidal rule.

\section{Islet tissue- and glucose-stimulated insulin secretion}

Rat pancreas digestion, islet isolations, and static insulin secretion assays were performed as described previously (Sweet et al. 2004, Niswender et al. 2005, Sweet \& Gilbert 2006). Purified islets were cultured in RPMI-1640 culture media with $10 \%$ fetal bovine serum at $37^{\circ} \mathrm{C}$ in humidified air $\left(5 \% \mathrm{CO}_{2}\right)$ for 18 to $24 \mathrm{~h}$. The assessment of insulin secretion in static media was carried out as follows. Islets were handpicked twice into a Petri dish containing KRB buffer (with $3 \mathrm{mM}$ glucose and $0 \cdot 1 \% \mathrm{BSA}$ ) and pre-incubated for $60 \mathrm{~min}$ $\left(37^{\circ} \mathrm{C}\right.$ and $\left.5 \% \mathrm{CO}_{2}\right)$. Subsequently, batches of 100 islets (in quadruplicate) were transferred into 96-well plates containing $200 \mu \mathrm{l} \mathrm{KRB}$ with either 3 or $20 \mathrm{mM}$ glucose, with or without $100 \mathrm{nM}$ DTBZ and incubated for $60 \mathrm{~min}$. The supernatant was removed and the insulin was measured using ELISA (ALPCO, Windham, NH, USA).

\section{The effect of DTBZ on dipeptidyl peptidase IV(DPP-IV)}

The effect of DTBZ on DDP-IV was determined by DPP profiling service from BPS Bioscience, Inc. (San Diego, CA, USA).

\section{Dopamine measurements}

Anesthetized rats received an i.v. injection of TBZ and were killed one hour later. Euthanasia was performed by exsanguination of the anesthetized animal. Brain and pancreas were harvested as quickly as possible and frozen at $-80{ }^{\circ} \mathrm{C}$ until use. Frozen tissue was pulverized in a liquid nitrogencooled mortar and extracted in $0.01 \mathrm{M} \mathrm{HCl}$. The tissue extract was centrifuged at $10000 \mathrm{~g}$ at $4{ }^{\circ} \mathrm{C}$ to remove debris and the total protein was estimated by reading the absorbance at $280 \mathrm{~nm}$. The concentration of dopamine in the extract was estimated using an ELISA kit from Rocky Mountain Diagnostics (Colorado Springs, CO, USA) as per the manufacturer's instructions and normalized to the extract protein concentration.

Quantitation of VMAT2 mRNA in pancreata and islets of Lewis rats The harvesting of pancreata was performed as follows; anesthetized rats were opened with a midline incision and the liver stomach and small intestines reflected to expose the pancreas. The cavity was then bathed 
with $10 \mathrm{ml}$ of a $1: 1$ solution PBS $1 \times$ and RNAlater (Ambion, Austin, TX, USA). The pancreas was dissected and transferred to a $50 \mathrm{ml}$ polypropylene tube containing $6 \mathrm{ml}$ fresh RNAlater solution and if not immediately processed was stored at $-80^{\circ} \mathrm{C}$. After thawing, the entire pancreas was transferred into $1 \mathrm{ml}$ QIAzol (Qiagen)/100 mg tissue and homogenized. In the indicated experiments, purified and hand-picked rat islets (about 500) were transferred directly to QIAzol. Total RNA, either from pancreata or from purified islets, was purified using the RNeasy Mini Kit in conjunction with the RNase-Free DNase Set, both from Qiagen. All RNA extractions were performed using RNase-/DNase-free laboratory ware. RNA was quantified and assessed for purity by electrophoresis on a $1 \cdot 6 \%$ agarose gel and u.v. spectrophotometry. Tissue processing, RNA extraction, and qRT-PCR assay setup were performed in separate designated laboratory areas to prevent cross-contamination. All reverse transcriptase reactions were performed using the SuperScript III RT System from Invitrogen with random-priming. The qPCR assays were performed using the amount of cDNA obtained retro-transcribing 100 ng total RNA. The QuantiTect SYBR Green PCR Kit (Invitrogen) was used to perform all the reactions in presence of $0.2 \mu \mathrm{M}$ primers, in a total volume of $25 \mu \mathrm{l}$. The samples were amplified with a precycling hold at $95^{\circ} \mathrm{C}$ for $15 \mathrm{~min}$, followed by 36 cycles of denaturation at $95{ }^{\circ} \mathrm{C}$ for $15 \mathrm{~s}$, annealing at $55-60{ }^{\circ} \mathrm{C}$ (depending from the primers) for $30 \mathrm{~s}$, and extension at $72{ }^{\circ} \mathrm{C}$ for $20 \mathrm{~s}$. qRT-PCR reagent controls (reagents without any template or with $100 \mathrm{ng}$ of not retro-transcribed RNA) were included in all the assays. Each assay was run in triplicates and repeated at least twice to verify the results, and the mean copy number was used for analysis. The S.D. between assays was not significant (5\%) in all the experiments. The relative amount of specific transcripts was calculated as described previously (Maffei et al. 2004). To correct for sample to sample variations in qRT-PCR efficiency and errors in sample quantitation, the level of both GAPDH transcripts and 18S rRNA was tested for use in normalization of specific RNA levels. In these experiments no significant differences were found between normalization by GAPDH mRNA level or normalization by $18 \mathrm{~S}$ rRNA levels. All oligonucleotides were synthesized by Invitrogen. The primer sequences are as follows: $5^{\prime}$-CGC AAA CTG ATC CTG TTC AT-3' (VT2-2 F) and $5^{\prime}$-AGA AGA TGC TTT CGG AGG TG-3' (VT2-2 R); 5'-AAC GGA TTT GGC CGT ATC GGA C-3' (rGAPDH F) and 5'-TCG CTC CTG GAA GAT GGT GAT G-3' (rGAPDH R); 5'-TTS GAA CGT CTG CCC TAT CAA-3' (r18S F) and $5^{\prime}$-CAA TTA CAG GGC CTC GAA AG-3' (r18S R). The relative amounts of mRNA were calculated by the comparative cycle threshold method described by Livak \& Schmittgen (2001).

Quantitation of VMAT2 and preproinsulin protein in pancreas lysates by western blot Western blot analysis was conducted on pancreas tissue obtained from control and diabetic STZ-treated rats using standard procedures. Briefly, sample tissues were flash-frozen in liquid nitrogen and ground to a fine powder while frozen. Powdered proteins were solubilized in $1 \times$ PBS, $1 \%$ Nonidet P-40, $0.5 \%$ sodium deoxycholate, and $0 \cdot 1 \%$ SDS. A complete cocktail of mammalian protease inhibitors (Sigma-Aldrich), at high concentration, was added immediately prior to sample preparation. Protein concentrations were determined using a Bio-Rad protein assay (Bio-Rad, Inc.) with BSA standards and following the manufacturer's recommendations. Solubilized proteins were diluted in Laemmli sample buffer and incubated at $100{ }^{\circ} \mathrm{C}$ for $1 \mathrm{~min}$. Protein separation was conducted using the Bio-Rad Lab Mini-gel electrophoresis system on $15 \%$ acrylamide/bis gels. Proteins were then transferred onto Immobilon-PVDF membranes using the same system. Membranes were prepared for immunoblotting by washing in TTBS (10 mM Tris-Glycine (pH 8•0), 0.15 M $\mathrm{NaCl}$, with $0 \cdot 05 \%$ (w/v) Tween-20). Membranes were then blocked in TTBS plus $5 \%(\mathrm{w} / \mathrm{v})$ non-fat dry milk. The membranes were separated into high $(>15 \mathrm{kDa})$ and low MW $(<15 \mathrm{kDa}$ ) ranges. Membranes were probed for specific proteins by overnight incubation with either a 1:1000 dilution of rabbit anti-VMAT2 primary antibody (Chemicon International, Temecula, CA, USA) or a 1:400 dilution antiinsulin primary antibody (Abcam, Cambridge, MA, USA). The membranes were then washed thrice in TTBS and developed with 1:5000 dilution of either donkey anti-rabbit Igs or sheep anti-mouse Igs conjugated to horseradish peroxidase (Amersham Bioscience). After one hour, the membranes were washed in TTBS and a chemiluminescent substrate solution was added (Immobilon Western Solution (Millpore, Bedford, MA, USA). The membranes were then used to expose Bio-Max film (Eastman Kodak).

\section{Statistical analysis}

All results are presented as means \pm S.E.M., or as indicated in the text. The Student's $t$-test was performed for assessing statistical significance of differences. All $P$ values are two-tailed.

\section{Results}

\section{Glucose tolerance in Adult Lewis rats is improved by TBZ}

Older heavier Lewis rats display glucose intolerance relative to younger animals during an IPGTT (Wang et al. 1997, Natalucci et al. 2003). To explore the role of VMAT2 in insulin secretion and to better demonstrate the possible value of VMAT2 as a potential therapeutic target, we selected older male Lewis rats (300-500 g, > 11 weeks of age) for IPGTT testing. For this study, only rats with vehicle-alone area under the curve (AUC) IPGTT values greater than $10 \mathrm{~g} / \mathrm{dl} \times \mathrm{min}$ were used. We selected a dose of TBZ approximately threeto tenfold higher than the equivalent doses presently used in humans to treat movement disorders (Kenney \& Jankovic 
2006). Following TBZ administration (about $1 \mathrm{~h}$ ), but before glucose challenge, we did not find reproducible differences in the baseline fasting glucose concentrations of control animals (data not shown). Following TBZ treatment and glucose challenge, however, we found a significant change in the shape of the glucose disposition curve during IPGTT (Fig. 1, top panel).

A comparison of the AUC during IPGTT revealed that TBZ reduced the glucose excursion by $\sim 35 \%$ at $2 \cdot 25 \mu \mathrm{g} / \mathrm{g}$ body weight (Fig. 1, bottom panel). This dose represented a maxima of the glucose tolerance enhancing effects of TBZ; at doses lower than $0.3 \mathrm{mg} / \mathrm{kg}$, the effects of TBZ became undetectable by this assay, and at doses higher than $5.0 \mathrm{mg} / \mathrm{kg}$, the AUC IPGTT became increasingly variable, often surpassing that of control levels. Chronic administration of TBZ at $\sim 0 \cdot 1 \mathrm{mg} / \mathrm{kg}$ body weight for 5 days suppressed the AUC IPGTT in a fashion similar to the single high dose (data not shown).
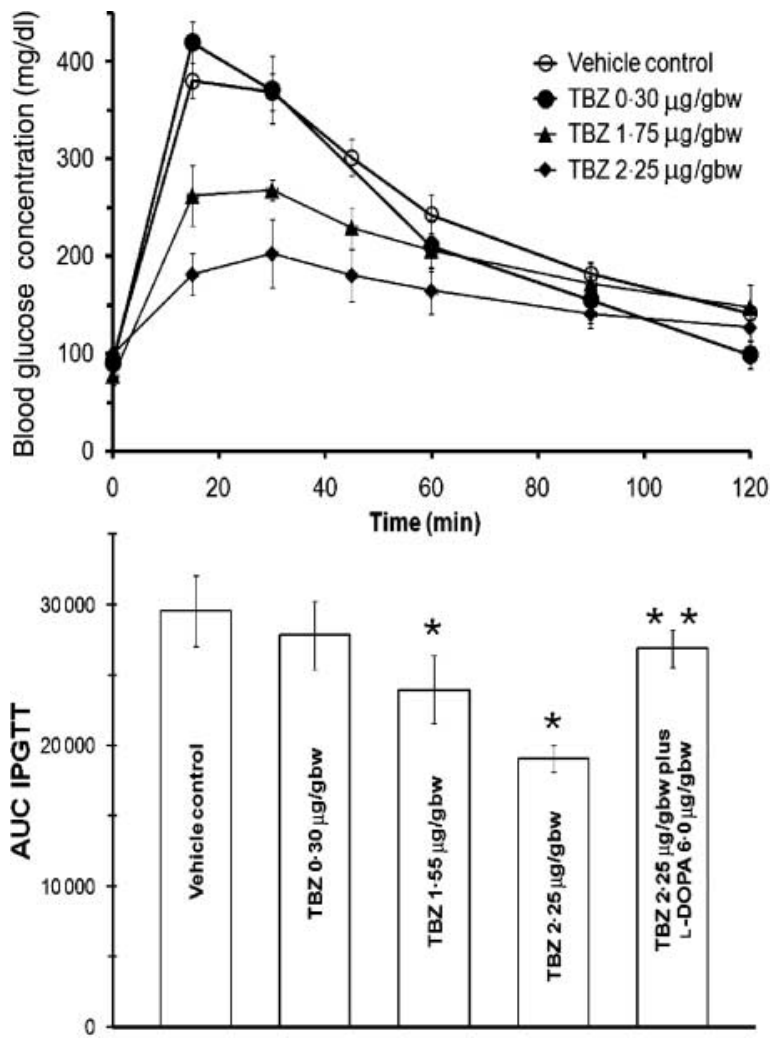

Figure 1 Tetrabenazine reduces the blood glucose excursion during IPGTT. Top panel. Blood glucose values during IPGTT of Lewis rats treated with vehicle alone (open symbol) or with tetrabenazine at the indicated doses. Error bars indicate the S.E.M. $(n=25)$ at the indicated dose (closed symbols). Bottom panel. Results presented as AUC IPGTT. The asterisk indicates AUC IPGTT for vehicle controls $(n=25)$ was significantly higher than the AUC IPGTT of the same TBZ-treated animals $(n=25)(P<0 \cdot 05)$. The double asterisk indicates that the AUC IPGTT following treatment with TBZ and L-DOPA was significantly different than that of TBZ alone $(n=6)$. Error bars represent S.E.M.
$T B Z$ depletes total pancreatic dopamine and $L-D O P A$ reverses effects of $T B Z$

Dopamine is a well-known substrate of VMAT2-mediated vesicular transport (Howell et al. 1994) and one of the main reported actions of TBZ is the depletion of dopamine in the brain tissue (Kenney \& Jankovic 2006). To explore the possible role of dopamine in mediating the in vivo glucose tolerance enhancing effects of TBZ, we examined the effects of TBZ on the concentration of dopamine in both the pancreas and the brain. One hour after injection of TBZ, the dopamine content of both the tissues was significantly reduced (Fig. 2). As islets compose only about $2 \%$ of the pancreas, the marked effects of TBZ on the total pancreatic dopamine content is likely to reflect dopamine depletion in non-islet pancreatic tissue elements as well. We next repeated the IPGTT experiments with TBZ. In these experiments, however, L-DOPA, the metabolic precursor of dopamine or a vehicle control, was administered an hour following TBZ and concurrent with glucose. We found that L-DOPA $(6.0 \mathrm{mg} /$ $\mathrm{kg}$, i.p.) was able to reverse the effects of TBZ, increasing the AUC IPGTT to slightly below the control levels (Fig. 1, bottom panel).

\section{TBZ enhances in vivo glucose-dependent insulin secretion}

We next tested the hypothesis that the smaller glucose excursions in IPGTT seen after the administration of TBZ were due to increased insulin concentrations in the plasma following glucose stimulation. We measured BG, plasma insulin, and glucagon concentrations in blood samples obtained during IPGTT (Fig. 3A-D). We found that the AUC for both insulin and glucagon measurements were changed by the administration of TBZ. Plasma insulin amounts were significantly greater following a single dose of
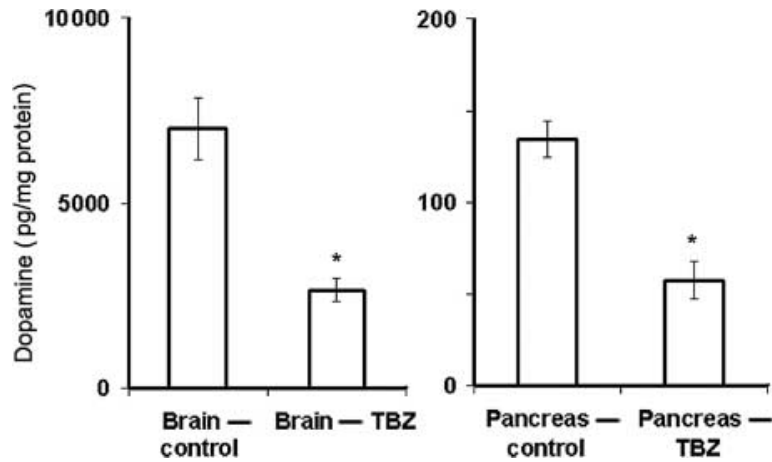

Figure 2 TBZ reduces the dopamine content of brain and pancreas tissue. Tetrabenazine at $1.5 \mathrm{mg} / \mathrm{kg}$ body weight was administered i.v. to Lewis rats. One hour later, the animals were killed and the brains and pancreata harvested and extracted in a buffer. The dopamine concentration in the extract was determined by ELISA and normalized to the total protein content. The error bars represent the S.E.M. from measurements of three TBZ-treated and three control Lewis rats. An asterisk represents a significant difference $(P<0 \cdot 05)$ from control. 

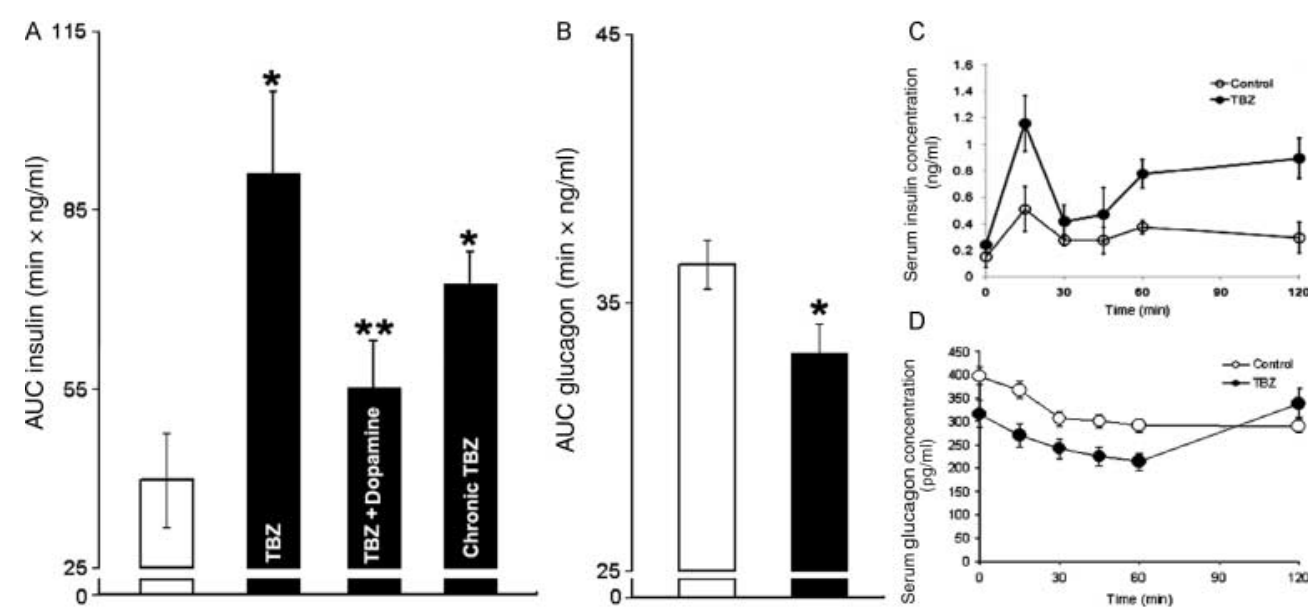

Figure 3 Tetrabenazine alters glucose stimulated insulin and glucagon secretion in vivo. Plasma insulin (A and C) and glucagon concentrations (B and D) were measured during IPGTT of Lewis rats ( $>11$ weeks old) $(n=6)$ treated with vehicle alone (open columns and circles). One week later, a second IPGTT was performed with TBZ $(2 \cdot 25 \mathrm{mg} / \mathrm{kg}$ body weight) (filled columns and circles), TBZ $(2 \cdot 25 \mathrm{mg} / \mathrm{kg}$ body weight) plus dopamine $(6.0 \mathrm{mg} / \mathrm{kg})$, or following five daily injections TBZ $(0 \cdot 3 \mathrm{mg} / \mathrm{kg}$ body weight). An asterisk represents a significant difference $(P<0 \cdot 05)$ from control.

TBZ or chronic low doses of TBZ $(0 \cdot 1 \mathrm{mg} / \mathrm{kg}$ body weight/ day $\times 5$ days) and glucose challenge relative to the vehicletreated controls. In addition, we found that i.v. dopamine, given at the same time as glucose, partially blocked the insulin enhancing effects of TBZ (Fig. 3A).The AUC plasma glucagon measurements were lower relative to controls following i.v. TBZ administration and glucose challenge (Fig. 3B and D). The change in AUC glucagon, however, was less than the change in AUC insulin. In STZ-treated rats that maintained glucose dependant insulin secretion, TBZ $(1.5 \mathrm{mg} / \mathrm{kg})$ increased the AUC insulin measurement by $\sim 50-80 \%$ and decreased AUC IPGTT (data not shown).

TBZ enhances in vitro glucose-dependent insulin secretion in purified rat islets

Since VMAT2 is located throughout the CNS and glucose homeostasis is regulated by the autonomic nervous system, a critical question in this study was whether TBZ was acting locally in the islets. We next tested whether the VMAT2 antagonist DTBZ, the direct and active metabolite of TBZ, could enhance insulin secretion in purified rat islets tested in vivo. The islets were incubated in high- and low-glucose media with and without DTBZ. The insulin secretion increased tenfold in response to glucose and was significantly further enhanced by DTBZ two- to threefold $(P<0 \cdot 05)$ (Fig. 4). At low glucose, an increase in insulin secretion mediated by DTBZ was not statistically significant.

\section{DTBZ does not act through DPP-IV inhibition}

DTBZ structurally belongs to a class of quinolizine alkaloids. Recently, some of the quinolizine alkaloids have been shown to increase insulin levels through inhibiting DDP-IV, a serine protease that cleaves the insulin-stimulating incretin hormone glucagon-like peptide-1 (Lubbers et al. 2007). To examine whether DPP-IV plays a role in DTBZ's insulin enhancement, we tested DTBZ's effect on DDP-IV in vitro. DTBZ had no effect on DPP-IV at concentrations up to $10 \mu \mathrm{M}$ (data not shown).

\section{VMAT2 is expressed in rodent islets and $\beta$-cells}

As opposed to VMAT2 expressed by human $\beta$-cells (Anlauf et al. 2003), the presence of VMAT2 in rodent islets cannot be detected by immunohistochemistry using the presently

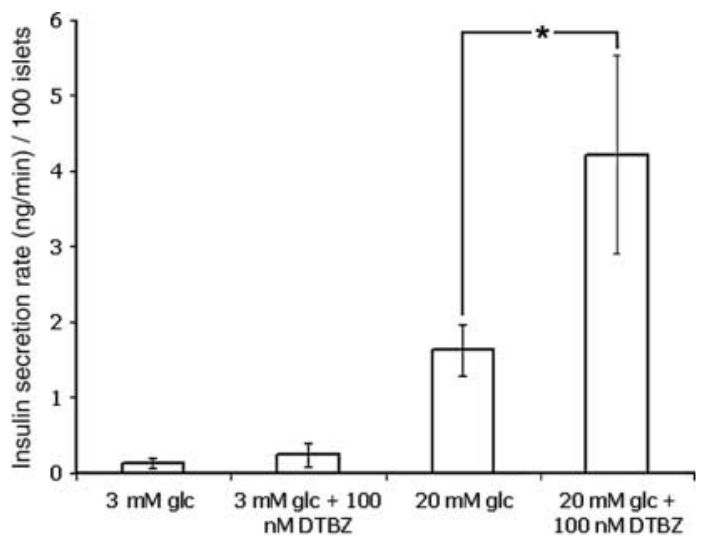

Figure 4 DTBZ enhances glucose-stimulated insulin secretion in rat islets ex vivo. Hand-picked purified islets were cultured in high- or low-glucose containing media with and without DTBZ. Serial insulin concentration measurements in the supernatant were performed and the means and S.E.M. calculated. An asterisk represents a significant difference $(P<0 \cdot 05)$ from control. 
available commercial antisera. To demonstrate that VMAT2 is associated with rat islets, we performed the following series of experiments. First, total RNA was prepared from brain, purified islets obtained from rodent pancreata, and total pancreas. Total RNA was then reverse-transcribed and amplified with specific primers for rat VMAT2. We were able to amplify and sequence a $175 \mathrm{bp}$ cDNA fragment of the length and structure expected from the published sequence of rat VMAT2 (Erickson et al. 1992) (Fig. 5A). Total RNA from brain was used as a positive control (A, lane 1). Quantitation of specific VMAT2 transcripts in islets total RNA versus complete pancreas total RNA showed that VMAT2-specific RNA was enriched more than tenfold in islets relative to total pancreas (Fig. 5A, lane 2 versus lane 3). In the absence of the reverse transcription reaction, no PCR product was found (Fig. 5A, lane 4). Within the pancreas, insulin producing $\beta$-cells uniquely express the GLUT2 transporter. The toxin
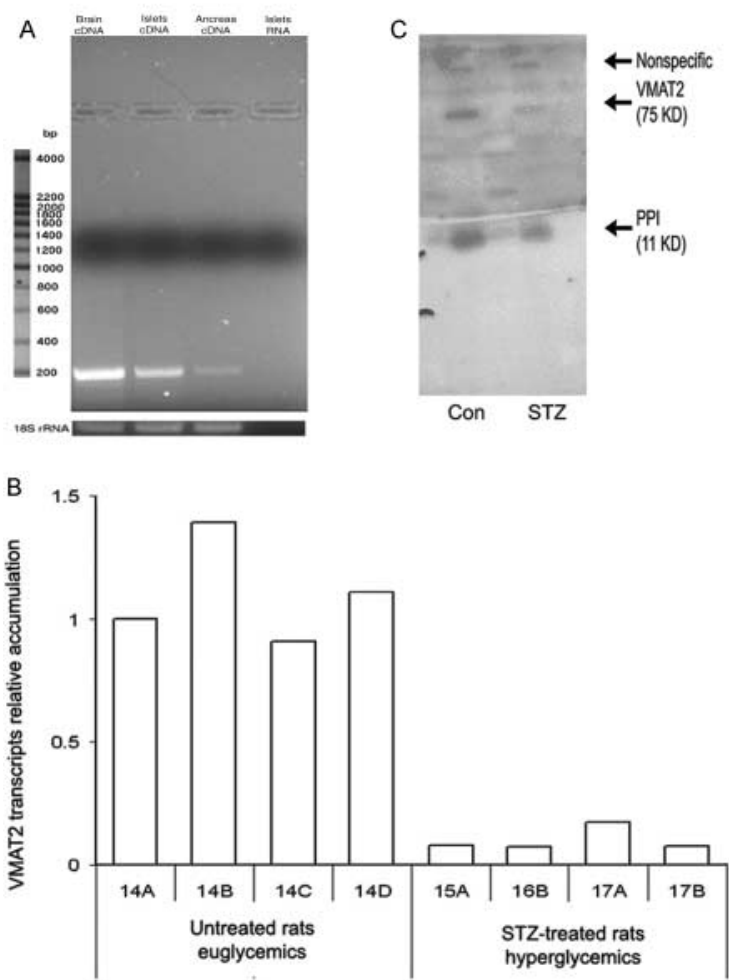

Figure 5 VMAT2 mRNA and protein in islets and pancreas of control and streptozotocin-treated Lewis rats. (A) Products of the qRT-PCR assay on total RNA from brain, purified islets, and total pancreas using VMAT2 primers that specifically amplify a $175 \mathrm{bp}$ fragment. Untranscribed RNA from purified islets is used as a control. GelPilot $200 \mathrm{bp}$ ladder is the molecular weight standard. (B) Relative accumulation of VMAT2 mRNA in pancreata of control and streptozotocin-induced diabetic Lewis rats. The average accumulation of VMAT2 mRNA in streptozotocin-treated rodents was approximately eightfold lower than the average accumulation in untreated pancreata $(P<0 \cdot 005)$. (C) Western blot analysis of VMAT2 expression in protein lysates prepared from control and streptozotocin-induced diabetic Lewis rats. streptozotocin selectively targets and destroys $\beta$-cells following the transport by GLUT2 (Elsner et al. 2000, Szkudelski 2001). To demonstrate that VMAT2 is associated with $\beta$-cells of the endocrine pancreas, we took advantage of the selective $\beta$-cell toxicity of streptozotocin. We prepared total RNA from pancreata obtained from four control rats and four streptozotocin-induced diabetic rats. Quantitation of VMAT2 message by real-time PCR showed that treatment with streptozotocin significantly reduced the amount of VMAT2 in diabetic pancreata relative to control pancreata 84-92\% (99.9\% CI) (Fig. 5B). When protein lysates were prepared from pancreata obtained from control rats and streptozotocin-induced diabetic rats, separated by SDSPAGE, transferred to membranes and then probed with VMAT2 antibodies, the loss of VMAT2 protein, as well as the preproinsulin protein, following STZ treatment was visible by the loss of the western blotting signal (Fig. 5C).

\section{Discussion}

In this report, we provide the evidence that VMAT2 expressed in $\beta$-cells of the endocrine pancreas plays a role in the regulation of insulin production and glucose homeostasis in vivo. We further provide evidence that the glucose tolerance enhancing effects of TBZ is mediated by the depletion of dopamine following the antagonism of VMAT2. Our studies focused on dopamine as the most likely intermediate mediator of the effects of TBZ, although it is not ruled out that other monoamines, such as serotonin, etc. also play a role in the observed in vivo effects of TBZ.

Several previous studies have demonstrated a link between insulin secretion and dopamine. For example, the treatment of Parkinson's patients with dopamine precursor, L-DOPA, reduces insulin secretion in glucose tolerance tests (Rosati et al. 1976). In rodent experiments, i.v. administration of L-DOPA inhibits glucose-stimulated insulin secretion (Ericson et al. 1977, Zern et al. 1980). In culture, analogs of dopamine inhibit glucose-stimulated insulin release by purified islets (Arneric et al. 1984). Most recently, Rubi et al. (2005) demonstrated that mouse $\beta$-cells (INS-1E cells), as well as purified rat and human islets, express the dopamine D2 receptor. In these cells and tissues, the D2 receptor was shown to co-localize with insulin in secretory granules in a pattern similar to the co-localization of VMAT2 and insulin (Anlauf et al. 2003). Both dopamine and the D2-like receptor agonist, quinpirole, inhibited glucose-stimulated insulin secretion when tested in primary rat $\beta$-cells, and rat, mouse, and human pancreatic islets.

Together with the studies of Rubi et al. (2005) and others (Brodoff \& Kagan 1972), the following model for the role of VMAT2 in islet function can be proposed. Dopamine produced locally in the $\beta$-cell cytoplasm is normally transported and stored in insulin-containing vesicles. In the presence of TBZ, the vesicular storage of dopamine declines. Under normal glucose-stimulated insulin secretion, 
dopamine is co-released with insulin and acts either in an autocrine or in a paracrine fashion to limit glucose-stimulated insulin secretion by other local $\beta$-cells. In the presence of TBZ, this negative feedback loop is not present and less dopamine is released with insulin and other local $\beta$-cells remain uninhibited by dopamine.

Presently, arginine pulse stimulation of insulin secretion is a gold standard measurement for evaluating functional $\beta$-cell mass. Our preliminary studies with TBZ suggest that more detailed glucose clamp and insulin secretion measurements should be performed and we are evaluating whether inhibition of VMAT2 might further improve the hyperglycemic clamp technique applied to evaluating $\beta$-cell mass. Although our studies are incomplete, we find that repeated low doses of TBZ may also be active in reducing glucose excursions. In other studies we find some evidence from PET pharmacokinetic studies that DTBZ may accumulate in the pancreas. Together, these data suggest that chronic low doses of TBZ may also result in the antagonism of VMAT2. Lastly, our observations must be interpreted carefully. TBZ has been used to treat movement disorders for over 30 years (Kenney \& Jankovic 2006) and effects on glucose homeostasis have not been reported. Nevertheless, our findings suggest that VMAT2 plays a role in glucose homeostasis and could be a therapeutic target in diabetes.

\section{Declaration of Interest}

The authors have no financial or other arrangements that represent a conflict of interest.

\section{Funding}

This work was supported by grants from the PHS, NIH, DK63567, DK66518, Telethon It - JDRF GJT04003; University of Washington DERC (DK 17047) and the Columbia University DERC (DK063608).

\section{Acknowledgements}

The authors would like to thank Drs T Debruin and M Kilbourn for their critical review of the manuscript.

\section{References}

Adeghate E \& Donath T 1991 Dopamine-beta-hydroxylase-positive nerves in normal and transplanted pancreatic tissue in the anterior eye-chamber of rats. Journal of Chemical Neuroanatomy 4 223-227.

Ahren B 2000 Autonomic regulation of islet hormone secretion-implications for health and disease. Diabetologia 43 393-410.

Ahren B \& Lundquist I 1985 Effects of L-dopa-induced dopamine accumulation on $45 \mathrm{Ca}^{2+}$ efflux and insulin secretion in isolated rat islets. Pharmacology 30 71-82.

Ahren B, Jarhult J \& Lundquist I 1981 Influence of the sympatho-adrenal system and somatostatin on the secretion of insulin in the rat. Journal of Physiology 312 563-575.
Aleyassine H \& Gardiner RJ 1975 Dual action of antidepressant drugs (MAO inhibitors) on insulin release. Endocrinology 96 702-710.

Anlauf M, Eissele R, Schafer MK, Eiden LE, Arnold R, Pauser U, Kloppel G \& Weihe E 2003 Expression of the two isoforms of the vesicular monoamine transporter (VMAT1 and VMAT2) in the endocrine pancreas and pancreatic endocrine tumors. Journal of Histochemistry and Cytochemistry 51 1027-1040.

Arneric SP, Chow SA, Long JP \& Fischer LJ 1984 Inhibition of insulin release from rat pancreatic islets by drugs that are analogues of dopamine. Diabetes 33 888-893.

Barker CJ, Leibiger IB, Leibiger B \& Berggren PO 2002 Phosphorylated inositol compounds in $\beta$-cell stimulus-response coupling. American Journal of Physiology. Endocrinology and Metabolism 283 E1113-E1122.

Borelli MI \& Gagliardino JJ 2001 Possible modulatory effect of endogenous islet catecholamines on insulin secretion. BMC Endocrine Disorder 11

Borelli MI, Villar MJ, Orezzoli A \& Gagliardino JJ 1997 Presence of DOPA decarboxylase and its localisation in adult rat pancreatic islet cells. Diabetes and Metabolism 23 161-163.

Borelli MI, Rubio M, Garcia ME, Flores LE \& Gagliardino JJ 2003 Tyrosine hydroxylase activity in the endocrine pancreas: changes induced by shortterm dietary manipulation. BMC Endocrine Disorder 32.

Brice NL, Varadi A, Ashcroft SJ \& Molnar E 2002 Metabotropic glutamate and $\mathrm{GABA}(\mathrm{B})$ receptors contribute to the modulation of glucosestimulated insulin secretion in pancreatic beta cells. Diabetologia 45 242-252.

Brodoff BN \& Kagan A 1972 Biogenic-amines and diabetes in Sand rat. Hormone and Metabolic Research 4 310-311.

Brunicardi FC, Shavelle DM \& Andersen DK 1995 Neural regulation of the endocrine pancreas. International Journal of Pancreatology 18 177-195.

Cegrell L 1968 The occurrence of biogenic monoamines in the mammalian endocrine pancreas. Acta Physiologica Scandinavica 314 1-60.

Duttaroy A, Zimliki CL, Gautam D, Cui Y, Mears D \& Wess J 2004 Muscarinic stimulation of pancreatic insulin and glucagon release is abolished in $\mathrm{m} 3$ muscarinic acetylcholine receptor-deficient mice. Diabetes 53 1714-1720.

Eiden LE, Schafer MK, Weihe E \& Schutz B 2004 The vesicular amine transporter family (SLC18): amine/proton antiporters required for vesicular accumulation and regulated exocytotic secretion of monoamines and acetylcholine. Pflugers Archiv 447 636-640.

Ekholm R, Ericson LE \& Lundquist I 1971 Monoamines in the pancreatic islets of the mouse. Subcellular localization of 5-hydroxytryptamine by electron microscopic autoradiography. Diabetologia 7 339-348.

El-Mansoury AM \& Morgan NG 1998 Activation of protein kinase C modulates $\alpha 2$-adrenergic signalling in rat pancreatic islets. Cellular Signalling $10637-643$.

Elsner M, Guldbakke B, Tiedge M, Munday R \& Lenzen S 2000 Relative importance of transport and alkylation for pancreatic $\beta$-cell toxicity of streptozotocin. Diabetologia 43 1528-1533.

Erickson JD, Eiden LE \& Hoffman BJ 1992 Expression cloning of a reserpinesensitive vesicular monoamine transporter. PNAS 89 10993-10997.

Erickson JD, Schafer MK, Bonner TI, Eiden LE \& Weihe E 1996 Distinct pharmacological properties and distribution in neurons and endocrine cells of two isoforms of the human vesicular monoamine transporter. PNAS 93 5166-5171.

Ericson LE, Hakanson R \& Lundquist I 1977 Accumulation of dopamine in mouse pancreatic $\beta$-cells following injection of L-DOPA. Localization to secretory granules and inhibition of insulin secretion. Diabetologia 13 $117-124$

Feldman JM \& Chapman B 1975a Characterization of pancreatic islet monoamine oxidase. Metabolism 24 581-588.

Feldman JM \& Chapman B $1975 b$ Monoamine oxidase inhibitors: nature of their interaction with rabbit pancreatic islets to alter insluin secretion. Diabetologia 11 487-494

Hansen SE \& Hedeskov CJ 1977 Simultaneous determination of the content of serotonin, dopamine, noradrenaline and adrenaline in pancreatic islets isolated from fed and starved mice. Acta Endocrinologica 86 $820-832$ 
Hayashi M, Yamada H, Uehara S, Morimoto R, Muroyama A, Yatsushiro S, Takeda J, Yamamoto A \& Moriyama Y 2003 Secretory granule-mediated co-secretion of L-glutamate and glucagon triggers glutamatergic signal transmission in islets of Langerhans. Journal of Biological Chemistry 278 1966-1974.

Henquin JC 2000 Triggering and amplifying pathways of regulation of insulin secretion by glucose. Diabetes 49 1751-1760.

Howell M, Shirvan A, Stern-Bach Y, Steiner-Mordoch S, Strasser JE, Dean GE \& Schuldiner S 1994 Cloning and functional expression of a tetrabenazine sensitive vesicular monoamine transporter from bovine chromaffin granules. FEBS Letters 338 16-22.

Iturriza FC \& Thibault J 1993 Immunohistochemical investigation of tyrosine-hydroxylase in the islets of Langerhans of adult mice, rats and guinea pigs. Neuroendocrinology 57 476-480.

Kenney C \& Jankovic J 2006 Tetrabenazine in the treatment of hyperkinetic movement disorders. Expert Review of Neurotherapentics 6 7-17.

Lane JD, Smith JE, Shea PA \& McBride WJ 1976 Neurochemical changes following the administration of depleters of biogenic monoamines. Life Sciences 19 1663-1667.

Livak KJ \& Schmittgen TD 2001 Analysis of relative gene expression data using real-time quantitative PCR and the $2(-$ Delta Delta $\mathrm{C}(\mathrm{T}))$ method. Methods 25 402-408.

Lubbers A, Bohringer M, Gobbi L, Hennig M, Hunziker D, Kuhn B, Loffler B, Mattei P, Narquizian R, Peters J et al. 2007 1,3-Disubstituted 4-aminopiperidines as useful tools inthe optimization of the 2-aminobenzo[a]quinolizinedipeptidyl peptidase IV inhibitors. Bioorganic and Medicinal Chemistry Letters 17 2966-2970.

Lundquist I, Ahren B, Hansson C \& Hakanson R 1989 Monoamines in pancreatic islets of guinea pig, hamster, rat, and mouse determined by high performance liquid chromatography. Pancreas 4 662-667.

Maffei A, Liu Z, Witkowski P, Moschella F, Del Pozzo G, Liu E, Herold K, Winchester RJ, Hardy MA \& Harris PE 2004 Identification of tissuerestricted transcripts in human islets. Endocrinology 145 4513-4521.

Natalucci S, Ruggeri P, Cogo CE, Picchio V, Brunori A \& Burattini R 2003 Age-related analysis of glucose metabolism in spontaneously hypertensive and normotensive rats. Experimental Physiology 88 399-404.

Niswender CM, Willis BS, Wallen A, Sweet IR, Jetton TL, Thompson BR, Wu C, Lange AJ \& McKnight GS 2005 Cre recombinase-dependent expression of a constitutively active mutant allele of the catalytic subunit of protein kinase A. Genesis 43 109-119.

Pettibone DJ, Totaro JA \& Pflueger AB 1984 Tetrabenazine-induced depletion of brain monoamines: characterization and interaction with selected antidepressants. European Journal of Pharmacology 102 425-430.

Rosati G, Maioli M, Aiello I, Farris A \& Agnetti V 1976 Effects of long-term L-Dopa therapy on carbohydrate metabolism in patients with Parkinson's disease. European Neurology 14 229-239.

Rubi B, Ljubicic S, Pournourmohammadi S, Carobbio S, Armanet M, Bartley C \& Maechler P 2005 Dopamine D2-like receptors are expressed in pancreatic beta cells and mediate inhibition of insulin secretion. Journal of Biological Chemistry 280 36824-36832.
Scherman D 1986 Dihydrotetrabenazine binding and monoamine uptake in mouse brain regions. Journal of Neurochemistry 47 331-339.

Scherman D, Jaudon P \& Henry JP 1983 Characterization of the monoamine carrier of chromaffin granule membrane by binding of [2-3H]dihydrotetrabenazine. PNAS 80 584-588.

Shankar E, Santhosh KT \& Paulose CS 2006 Dopaminergic regulation of glucose-induced insulin secretion through dopamine D2 receptors in the pancreatic islets in vitro. IUBMB Life $\mathbf{5 8} 157-163$.

Souza F, Freeby M, Hultman K, Simpson N, Herron A, Witkowsky P, Liu E, Maffei A \& Harris PE 2006 Current progress in non-invasive imaging of beta cell mass of the endocrine pancreas. Current Medicinal Chemistry 13 2761-2773.

Storto M, Capobianco L, Battaglia G, Molinaro G, Gradini R, Riozzi B, Di Mambro A, Mitchell KJ, Bruno V, Vairetti MP et al. 2006 Insulin secretion is controlled by mGlu5 metabotropic glutamate receptors. Molecular Pharmacology 69 1234-1241.

Sweet IR \& Gilbert M 2006 Contribution of calcium influx in mediating glucose-stimulated oxygen consumption in pancreatic islets. Diabetes $\mathbf{5 5}$ 3509-3519.

Sweet IR, Cook DL, DeJulio E, Wallen AR, Khalil G, Callis J \& Reems J 2004 Regulation of ATP/ADP in pancreatic islets. Diabetes $\mathbf{5 3}$ 401-409.

Szkudelski T 2001 The mechanism of alloxan and streptozotocin action in B cells of the rat pancreas. Physiological Research 50 537-546.

Varoqui H \& Erickson JD 1997 Vesicular neurotransmitter transporters. Potential sites for the regulation of synaptic function. Molecular Neurobiology 15 165-191.

Wang Y, Perfetti R, Greig NH, Holloway HW, DeOre KA, MontroseRafizadeh C, Elahi D \& Egan JM 1997 Glucagon-like peptide-1 can reverse the age-related decline in glucose tolerance in rats. Journal of Clinical Investigation 99 2883-2889.

Weksler-Zangen S, Yagil C, Zangen DH, Ornoy A, Jacob HJ \& Yagil Y 2001 The newly inbred cohen diabetic rat: a nonobese normolipidemic genetic model of diet-induced type 2 diabetes expressing sex differences. Diabetes 50 2521-2529.

Wilson JP, Downs RW Jr, Feldman JM \& Lebovitz HE 1974 Beta cell monoamines: further evidence for their role in modulating insulin secretion. American Journal of Physiology 227 305-312.

Zern RT, Bird JL \& Feldman JM 1980 Effect of increased pancreatic islet norepinephrine, dopamine and serotonin concentration on insulin secretion in the golden hamster. Diabetologia 18 341-346.

Received in final form 24 March 2008

Accepted 10 April 2008

Made available online as an Accepted Preprint 10 April 2008 